
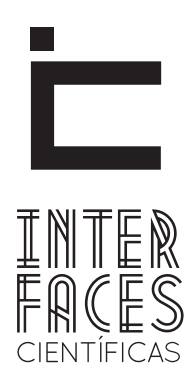

DIREITO

ISSN IMPRESSO 2316-3321

\title{
MULTICULTURALLSMO, MONISMO JURÍDICO E A QUESTÃO DO RECONHECIMENTO DOS DIREITOS HUMANOS DOS POVOS INDÍGENAS
}

\author{
JURIDICAL MONISM: STATE ENTRANCE TO THE EFFECTIVENESS OF HUMAN RIGHTS OF INDIGENOUS PEOPLES \\ MONISMO JURÍDICO: UN OBSTÁCULO PARA ESTADO EFECTIVO DE LOS DERECHOS HUMANOS DE LOS INDÍGENAS
}

Alessandra Matos Porttela ${ }^{1}$

\section{RESUMO}

O Estado brasileiro, desde os primórdios, nunca se preocupou com os direitos dos povos indígenas. A mudança de paradigma nesta questão só começou a ser alterada no início do século XX, mais precisamente em 1910, quando foi assinado o Decreto 8.072, criando o Serviço de Proteção aos Índios e Localização de Trabalhadores Nacionais (SPILTN), transformado em 1918 no Serviço de Proteção ao Índio (SPI). Apesar de outros documentos a partir deste marco histórico regularem a situação dos índios em território nacional, o fato é que nenhum deles reconheceu a cidadania destes povos, sendo estas nações alijadas de exercer e efetivar seus direitos fundamentais. Com o advento do multiculturalismo em fins do século passado, tal panorama começou a ser modificado, graças às lutas de minorias que exigiam participação política e reconhecimento jurídico de seus direitos. A Constituição da República Federativa do Brasil de 1988, incorporou em seu texto tais reivindicações, dedicando um capítulo exclusivo para tutelar os direitos indígenas. Internacionalmente, o Brasil assinou e ratificou decretos importantes que ampliaram os direitos dos povos indígenas, com vistas a dar-lhes dignidade. Efetivar o que está posto no âmbito legal tem sido, em verdade, o grande entrave para a coexistência harmônica e pacífica dos povos ameríndios para com o restante da "comunhão nacional", devido principalmente ao fato 
de o Brasil se negar a reconhecer a organização social ameríndia, seus sistemas jurídicos e suas sociedades como autônomas, uma vez que adota em sua matriz jurídico-constitucional o monismo jurídico.

\section{ABSTRACT}

The Brazilian State, from the beginning, never cared about the rights of indigenous peoples. The paradigm shift in this issue only began to change at the beginning of the 20th century, more precisely in 1910, when was signed Decree 8.072, creating the Service of Protection to Indians and Localization of National Workers (SPILTN), transformed in 1918 into the Service of Protection to the Indian (SPI). Although other documents from this historical landmark regulate the situation of indians in national territory, the fact is that none of them recognized the citizenship of these peoples, these nations being deprived of exercising and enforcing their fundamental rights. With the advent of multiculturalism at the end of the last century, this view began to be modified, thanks to the struggles of minorities that required political participation and legal recognition of their rights. The Constitution of the Federative Republic of Brazil of 1988 incorporated in its text such

\section{PALAVRAS-CHAVE}

Direitos dos Povos Indígenas. Cidadania Indígena. Dignidade. Monismo Jurídico.

claims, dedicating an exclusive chapter to protect indigenous rights. Internationally, Brazil has signed and ratified important decrees that have extended the rights of indigenous peoples with a view to giving them dignity. Effecting what has been established in the legal sphere has been, in fact, the great obstacle to the harmonious and peaceful coexistence of the Amerindian peoples with the rest of the "national communion", mainly due to the fact that Brazil refuses to recognize the social organization Amerindian, its legal systems and its societies as autonomous, since it adopts in its legal-constitutional matrix legal monism.

\section{KEY-WORDS}

Rights of Indigenous Peoples - Indigenous Citizenship - Dignity - Legal Monism

\section{RESUMEN}

El estado brasileño, desde el principio, nunca se preocupó por los derechos de los pueblos indígenas. El cambio de paradigma en este tema solo se ha cambiado a principios del siglo XX, más precisamente en 1910, cuando se firmó el Decreto 8072, creando el Serviço de Proteção aos Índios e Localização de Trabalhadores Nacionais (SPILTN), transformado en 1918 en el Serviço de Proteção ao Índio (SPI). Aunque otros documentos desde este punto de referencia periódica, regir la situación de los indígenas en el país, lo cierto es que ninguno de ellos reconoció la ciudadanía de estas personas, dejando estas naciones que de lado para hacer ejercicio y llevar a cabo sus derechos fundamentales. Con el advenimiento de la multiculturalidad a finales del siglo pasado, esta imagen comenzó a ser modificada gracias a las luchas de las minorías que exigían la participación política y el reconocimiento legal de sus derechos. La Constitución de la República Federativa del Brasil en 1988, que se incorpora en su texto tales demandas, dedicando un capítulo exclusivo para proteger los derechos indígenas. Internacionalmente, el Brasil firmó y ratificó decretos importantes que ampliaron los derechos de los pueblos indígenas, con el fin de darles dignidad. Cumplir con lo que se pone en el marco legal ha sido, de hecho, el mayor obstáculo para la convivencia armónica y pacífica de los pueblos amerindios hacia el resto de la "comunidad nacional”, debido principalmente al hecho de que Brasil 
se niega a reconocer la organización social amerindia, sus sistemas legales y sus sociedades como autónomo, ya que adopta en su monismo jurídico de la matriz legal y constitucional.

\section{INTRODUCÇ̃O}

É curial o ostracismo vivido pelos povos indígenas no território brasileiro desde o seu descobrimento. Considerados como selvagens, foram relegados à condição de incapazes e despossuídos de direitos, sendo as políticas públicas destinadas a esses agrupamentos humanos consideradas como uma graça, um favor, tutelados quase em grau de misericórdia.

Cidadania indígena era algo que não se mencionava, afinal, os índios enquanto incapazes e inimputáveis não podiam ser considerados cidadãos, possuidor de direitos e prerrogativas frente ao Estado brasileiro. A política destinada a esses povos era de cunho integracionista, sendo classificados segundo o nível de interação com a "comunhão nacional", variando de isolados, leia-se sem integração alguma, até integrados, quando partícipes dos valores morais, tradições, usos e costumes da sociedade dos ditos civilizados, havendo um meio termo entre estas categorias denominadas de "em integração", consoante disposto no art. $4^{\circ}$ do Estatuto do Î́ndio, ainda em vigor no Estado heterogêneo, multifacetado e plural como o brasileiro.

Esta situação discriminatória só veio a ser modificada, ao menos, em tese, no final do século passado, quando minorias étnicas, religiosas, de origem, raça, cor, de gênero, começaram a reivindicar seus lugares de direito no Estado multicultural e multiétnico brasileiro. Políticas públicas começaram a ser criadas para estes grupos de excluídos, sendo a Constituição da República Federativa do Brasil de 1988, indubitavelmente, um marco histórico neste sentido.

0 maior entrave, entretanto, hodiernamente, continua sendo a matriz constitucional do monismo jurídico adotado pelo ordenamento jurídico pátrio. Isto porque

\section{PALABRAS CLAVE}

Derechos de los Pueblos Indígenas - La ciudadanía indígena - Dignidad - El monismo jurídico

impede o reconhecimento da soberania das nações indígenas em território nacional, apesar das mesmas serem, de fato, sociedades à parte, constituídas por cosmologias díspares, dissonantes do resto da comunidade nacional. Seus sistemas de valores, normativos, tradições, línguas, usos e costumes destoam substancialmente da denominada "comunhão nacional".

O monismo jurídico acaba sendo, neste diapasão, um entrave à concretização dos direitos fundamentais dos povos indígenas no território brasileiro, atentando contra à dignidade dessas nações, que ficam impossibilitadas de exercerem os seus direitos individuais e coletivos de forma plena e autônoma, como previstos em normas e diplomas internacionais.

\section{A IDENTIFICAÇ̃̃O DO “SER INDÍGENA” NO DIREITO BRASILEIRO}

O conceito de índio não é pacífico de entendimento entre os membros da comunidade nacional. 0 imaginário popular ainda se encontra arraigado a conceitos construídos no período colonial, vendo-os como seres primitivos e inferiores.

A designação de índio, para a comunidade nacional, continua sendo, até o presente momento, a mesma de quando Cristóvão Colombo chegou à ilha de São Salvador, nas Bahamas, ou seja, definida e determinada por impregnação visual e genética, “[...] de modo que não poderia ser índio quem não fosse razoavelmente escuro-avermelhado, não tivesse cabelos negros e lisos, olhos levemente puxados e, se possível, com muita tinta no rosto e pouca roupa no corpo" (PONTES, 2012, p. 168). 
Consoante Manuela Carneiro da Cunha citada por Barreto (2011, p. 36): “Nosso imaginário - e, por que não dizer, nosso entendimento - está repleto desta correlação: índio é aquele ser que vive na selva, anda nu, é feroz, primitivo [...] ou, ao contrário, está em um museu vivo, é o "bom selvagem".

O legislador brasileiro, por sua vez, designou índio ou silvícola: "Todo indivíduo de origem e ascendência pré-colombiana que se identifica e é identificado como pertencente a um grupo étnico cujas características culturais o distinguem da sociedade nacional" (Lei 6.001/73, art. $3^{\circ}$ inc. I).

Nesse sentido, a Lei 6.001/73 confundiu índio e silvícola, como preleciona Manuela Carneiro da Cunha citada por Barreto (2011, p. 36) "como se todo índio fosse habitante da selva, desconsiderando a possibilidade, se não o fato, de que existem índios, sobrevivendo nas periferias das pequenas e grandes cidades".

Pontes (2012, p. 169) afirma que o legislador brasileiro levou em consideração três critérios para definir o índio, quais sejam: "a) autoconsideração ("que se identifica”); b) consideração da sociedade ("e é identificado"); e c) hereditariedade ("de origem e ascendência pré-colombiana)". O critério da hereditariedade, entretanto, não se encontra de acordo com a teoria antropológica moderna, que aponta como melhor critério de conceituação de "ser índio", o de autoidentificação étnica (PONTES, 2012, p. 169).

0 critério de hereditariedade, também, não encontra consonância com a prescrição normativa da Constituição brasileira de 1988, que protege o sentimento indígena, como mostram os antropólogos. Consoante aduz Pontes (2012, p. 170):

O espírito constitucional está permeado de infrangível consideração aos aspectos culturais do povo indígena, [...] há uma notória consideração com o exercício atual das tradições e culturas históricas dos índios como forma de inclui-las na conjuntura cultural brasileira.

Visto por outro prisma, Barreto (2011, p. 33) analisando 0 art. $3^{\circ}$, inc. I, da Lei 6.001/73, entendeu que os três critérios adotados na definição de índio, foram os seguintes:
Genealógico, quando se refere à "origem e ascendência pré-colombiana"; cultural, ao mencionar as "características culturais [que] o distinguem da sociedade nacional"; e, por fim, pertença étnica, na expressão "que se identifica e é identificado como pertencente a um grupo étnico”.

0 critério cultural, da mesma maneira que o critério genealógico (hereditário), não encontra guarida na visão antropológica moderna nem na Carta Magna brasileira, pois, consoante preleciona Manuela Carneiro da Cunha citada por Barreto (2011, p. 36), "traços culturais podem variar no tempo e no espaço, como de fato variam, sem que isto afete a identidade do grupo".

Desta forma, o que se deve levar em consideração na conceituação do índio é apenas e tão-somente o critério de autoidentificação étnica, o seu sentimento de pertença a um determinado grupo indígena, bem como o sentimento deste grupo para com este indivíduo que se sente e se autodenomina índio.

O Estatuto da Sociedade Indígena, Projeto de Lei $2.057 / 91$, seguindo esta premissa, já prevê o conceito de índio em seu art. 92 sem o critério da vinculação hereditária e cultural, entendendo que "índio é todo indivíduo que se identifica como pertencente a uma sociedade indígena e é por ela reconhecido como tal", não importando

[...] se o indivíduo tem origem indígena, se é ancestral dos povos pré-colombianos, pois o que importa é saber se aquele indivíduo se identifica e é considerado pelo meio que o circunda como um verdadeiro índio, como um verdadeiro perpetuador da cultura autóctone no vasto caldo cultural brasileiro, porque é isso que a Constituição quer preservar. (PONTES, 2012, p. 171).

A proposta presente no Projeto de Lei 2057/91 encontra-se em perfeita harmonia com a antropologia contemporânea, como ensina Barreto (2011, p. 34), “a qual elimina critérios raciais, inaceitáveis e realça a continuidade histórica e a autoidentificação como definidoras da etnia”.

Santos Filho (2012, p. 18) afirma que "a legislação indigenista brasileira se inclinou sempre pela exclusiva defesa dos interesses dos colonizadores sem preocupação ou respeito com a cultura dos índios que já habitavam as terras". 
Do mesmo modo Souza (2008, p. 1-2) afirma que o Estado brasileiro sempre pautou sua relação com os povos indígenas muito mais pela negação do que pelo reconhecimento de seus direitos, já que possuía interesse pelas terras que hoje ocupa aliada a concepção ideológica etnocentrista a respeito dos povos considerados primitivos, levando ao Estado a apostar na extinção dessas populações.

A Constituição Republicana de 1891, assim como a Constituição do Império, não continham nenhuma previsão legal sobre os direitos indígenas. Apenas em 1910 foi editado o Decreto 8.072, criando o Serviço de Proteção aos Índios e Localização de Trabalhadores Nacionais (SPILTN), transformado em 1918 no Serviço de Proteção ao Índio (SPI) (SANTOS FILHO, 2012, p. 18).

O Decreto 8.072

\begin{abstract}
[...] previa a demarcação das terras ocupadas pelos índios, que delas teriam usufruto exclusivo; estabelecia a colocação em prática de meios mais eficazes para evitar que civilizados invadissem terras de índios e reciprocamente; preconizava o respeito à organização interna das tribos, seus hábitos e instituições, e a promoção, sempre que possível, da restituição dos terrenos ocupados. (SANTOS FILHO, 2012, p. 37).
\end{abstract}

Em 1916, foi aprovado o Código Civil, que previa em seu art. $6^{\circ}$ a relativa capacidade dos índios para a prática de atos da vida civil e, em 1928, foi editado o Decreto 5.484, que regulava a situação dos índios nascidos em território nacional, com cinquenta artigos (SANTOS FILHO, 2012, p. 38).

Foi apenas a Constituição de 1934 "que tratou dos direitos dos povos indígenas, assegurando aos índios a posse de seus territórios, atribuindo à União a responsabilidade pela promoção da política indigenista", previsão esta mantida pelas Constituições de 1937 e 1946 (SANTOS FILHO, 2012, p. 40).

Em 1961 foi criado o Parque Nacional do Xingu, no governo do Presidente Jânio Quadros, tendo por fundamento a preservação das condições em que viviam diversos povos indígenas da Região do Xingu, incluindo o seu meio ambiente (ARAÚJO, 2006, p. 28).
A Constituição de 1967, além de reconhecer a posse das terras que habitavam aos silvícolas, também previu o direito ao usufruto exclusivo dos recursos naturais e de todas as utilidades neles existentes. Foi também no ano de 1967 que foi editada a Lei $n^{\circ}$ 5.371, a qual substituiu o Serviço de Proteção aos Índios (SPI) pela Fundação Nacional do Índio, tendo por finalidade (FUNAI):

[...] aplicar a política em prol do índio no território nacional; zelar pelo patrimônio indígena; fomentar estudos sobre populações indígenas que vivem em território brasileiro e garantir sua proteção; demarcar, assegurar e proteger as terras tradicionalmente ocupadas pelos índios. (SANTOS FILHO, 2012, p. 43).

\section{Araújo (2006, p. 31) afirma que}

\begin{abstract}
A FUNAI ergueu-se sobre os escombros do SPI, aproveitando inclusive a sua estrutura de pessoal, recursos etc. [...] Se algo de novo havia, quando aparecia, vinha na forma de funcionários sem nenhuma experiência de trabalho com os índios, provenientes de outros órgãos que, funcionando em Brasília, estavam sendo transferidos para outras partes do país.
\end{abstract}

O SPI foi extinto porque "enfrentou uma avalanche de denúncias sobre irregularidades administrativas, corrupção, gestão fraudulenta do patrimônio indígena, em especial dos recursos naturais das terras indígenas" (ARAÚJO, 2006, p. 31).

Em 1973 foi editada a Lei n 6.001,

\begin{abstract}
Conhecida como Estatuto do Índio, disciplinando as relações do Estado e da sociedade civil brasileira com os índios. Constituída por sessenta e oito artigos, divididos em sete títulos, essa lei regula a situação jurídica dos índios e das comunidades indígenas, com o propósito de preservar a sua cultura e "integrá-los", progressiva e harmoniosamente, à comunhão nacional (art.1 $\left.{ }^{\circ}\right)$ (SANTOS FILHO, 2012, p. 44).
\end{abstract}

O Estatuto do Índio possui o mesmo princípio contido no Código Civil de 1916, classificando os índios como relativamente incapazes, devendo ser tutelados pelo órgão indigenista estatal que de 1910 a 1967 era representado pelo SPI e, atualmente, é pela FUNAI. A 
tutela só cessa quando houver a integração dos indígenas à sociedade nacional (ESTEVES, 2012, p. 17).

Como preleciona Araújo (2006, p. 32),

O objetivo do Estatuto era fazer com que os índios paulatinamente deixassem de ser índios. Tratava-se, portanto, de uma lei cujos destinatários eram como "sujeitos em trânsito", portadores, por isso mesmo, de direitos temporários, compatíveis com a sua condição e que durariam apenas e enquanto perdurasse essa mesma condição.

\section{Silveira (2011, p. 55) adverte que}

A capacidade relativa do índio é, também, um reflexo das ideias positivistas, pois, pela Lei dos Três Estados de Auguste Comte, os índios estariam em um estágio inicial da escala civilizatória e, não teriam discernimento completo para responderem, por si próprios, perante os atos da vida civil.

O marco do direito constitucional indígena se deu apenas de 1988 com a Constituição cidadã, possuindo "um Capítulo composto de previsões concernentes aos índios onde foram delineados os contornos de como devem ser efetivadas as relações entre os índios, seus povos e o Estado brasileiro" (SANTOS FILHO, 2012, p. 45).

Preleciona Santos Filho (2012, p. 46) que a Constituição de 1988 é considerada um marco para os povos indígenas porque cria uma postura inovadora no ordenamento jurídico pátrio, abandonando uma política de perspectiva assimilacionista, reconhecendo aos índios o direito à diferença, tornando explícita a multietnicidade e multiculturalidade brasileira. Do mesmo modo aduz Scotti (2013, p. 491-492), reconhecendo que apenas a partir da “Constituição Cidadã” de 1988

O patrimônio cultural passou a ser considerado um direito dos povos indígenas e de toda a sociedade brasileira, não uma situação transitória, vestígio do passado a exigir superação pela modernização, mas uma garantia do multiculturalismo e um elemento central para a autocompreensão ética e nacional.

Santos Filho (2012, p. 46), citando Paulo de Bessa Antunes, ensina que:
Reconhecer aos índios sua organização social, costumes, línguas, crenças e tradições, o art. 231 alberga o direito à alteridade, ou seja, o direito de o índio ser diferente, o que implica a aceitação de que a cultura dos não-índios não é a única forma de cultura válida.

Em razão dessa nova orientação, diz Santos Filho (2012, p. 47), citando Orlando Vilas Boas Filho, “as populações indígenas deixam de ser encaradas a partir de sua futura integração à sociedade brasileira, e sim, a partir de si próprias, de modo a ganhar visibilidade".

Como aduz Silveira (2011, p. 58), “[...] é a Carta cidadã que, finalmente, põe um fim na categorização entre índios isolados e índios integrados, superando, definitivamente, as distinções impostas pelo Estatuto do Índio e valorizando a diversidade cultural brasileira".

O paradigma da integração foi abandonado pela Constituição de 1988 e, em seu lugar, foi erguido o paradigma da interação, cujo fundamento é precisamente a diferença (BARRETO, 2011, p. 42).

Em face deste novo contexto político-jurídico, Santos Filho (2012, p. 48) preleciona que "os dispositivos do Estatuto do Índio, lei 6.001/73, forjados sob a óptica assimilacionista, [...] não foram recepcionados pelo novo sistema constitucional implantado a partir de 1988".

Do mesmo modo assevera Roweder (2010, p. 219), afirmando que a Constituição Federal de 1988 "revogou, tacitamente, alguns artigos da lei $n^{0} 6.001 / 73$, principalmente no que os destituía da condição de povos etnicamente diferenciados".

Outra novidade relevante trazida pela Carta Magna brasileira de 1988 foi "a consagração do princípio de que as comunidades indígenas constituem-se em sujeitos coletivos de direitos coletivos" (SILVEIRA, 2011, p. 59). Neste diapasão, “a 'cidadania indígena' é uma 'cidadania plural', que abarca não apenas os direitos e garantias fundamentais de cada índio, mas os direitos comuns de toda a comunidade indígena" (SILVEIRA, 2011, p. 60).

Sob a égide da Constituição Federal de 1988, diversos diplomas legais relacionados aos índios foram editados, merecendo destaque o Decreto 22 de 04.02.1991; os Decretos 23, 24, 25 e 26 de 04.02.1991; o Decreto 1.141 de 19.05.1994; o Decreto 1.775 de 
08.01.1996 (revogou o Decreto 22 de 04.02.1991); o Decreto 3.108 de 30.06.1999; o Decreto 3.156 de 27.08.1999; a Lei 9.838 de 23.11.1999 e o Decreto 4.412 de 07.10.2012, todos em harmonia com a Constituição Cidadã (SANTOS FILHO, 2012, p. 53-54).

0 reconhecimento à diferença imposta pela Constituição de 1988 não se confunde com incapacidade; pelo contrário, "reconhece a "capacidade" do índio para ingressar em juízo na defesa de seus direitos, sem depender da intermediação” (BARRETO, 2011, p. 43).

Do mesmo modo o novo Código Civil brasileiro de 2002, que alterou 0 art. $6^{\circ}$ do Código Civil de 1916, prevê em seu art. $4^{\circ}$, parágrafo único, “que a capacidade dos índios será regulada por legislação especial, no momento o Estatuto do Índio, que deve ser aplicado no que não contrariar a Constituição de 1988 e a Convenção 169/OIT" (SANTOS FILHO, 2012, p. 54).

Barreto (2011, p. 40) afirma que o Código Civil de 2002 não representou apenas uma mudança de técnica legislativa, mas representou uma mudança substantiva na medida em que não tratou os índios como incapazes; reconheceu a capacidade dos índios, remetendo à legislação especial o dever de regulamentá-la de acordo com o novo paradigma posto pela Constituição de 1988.

Atualmente, existe o Projeto de Lei 2.057 de 1991 tramitando no Congresso Nacional, que dispõe sobre o Estatuto das Sociedades Indígenas, o qual

[...] abandona "os critérios de indianidade" contidos no art. $4^{\circ}$ do Estatuto do Índio. Apenas uma única vez (art. $7^{\circ}$ ) usa a expressão "índios isolados", mas mesmo assim para garantir-lhes a "integridade física e cultural" e o "direito de permanecerem como tais". (BARRETO, 2011, p. 40).

Barreto (2011, p. 34) ensina que o Estatuto das Sociedades Indígenas traz novidades interessantes, dentre as quais cita os artigos $2^{\circ}, 3^{\circ}$ e 92 , vejamos:

Art. $2^{\circ}$ Sociedades indígenas são grupos socialmente organizados, compostos de uma ou mais comunidades, que se consideram distintos da sociedade envolvente e mantém vínculos históricos com sociedades pré-colombianas.
Art. $3^{\circ}$ As sociedades indígenas têm personalidade jurídica de natureza pública de direito interno e sua existência legal independe de registro ou qualquer ato do Poder Público.

Art. 92 Índio é todo indivíduo que se identifica como pertencente a uma sociedade indígena e é por ela reconhecido como tal.

Barreto (2011, p. 34), citando João Pacheco Oliveira, preleciona que as propostas do Estatuto da Sociedade Indígena coadunam com a antropologia contemporânea, uma vez que elimina critérios raciais inaceitáveis e realça a autoidentificação como definidora da etnia.

Ressalte-se que o Estatuto das Sociedades Indígenas se encontra em tramitação no Congresso Nacional há 26 anos sem, até o presente momento, ter sido aprovado e sancionado pelo Presidente da República, permanecendo em vigor o anacrônico Estatuto do Índio de 1973 em completa desarmonia com a Carta Magna de 1988 que impõe o paradigma da interação em detrimento do paradigma da integração.

\section{3 À GUISA DE CONCLUSÃO: 0 RECONHECIMENTO DOS SISTEMAS JURÍDICOS INDÍGENAS DIANTE DO MONISMO ESTATAL}

A ideologia jurídica ocidental surge juntamente com os Estados modernos, dotando o conteúdo semântico do Direito de ideias como poder, coerção e controle, produzindo a crença de que o Estado é um elemento indispensável para garantir a ordem social.

Consoante ensina Wolkmer (2001, p. 26),

O fenômeno jurídico que florescerá na moderna cultura europeia ocidental, a partir do século XVII e XVIII, corresponderá à visão de mundo predominante no âmbito da formação social burguesa, de modo de produção capitalista, da ideologia liberal-individualista e da centralização política, através da figura de um Estado Nacional Soberano.

Ensina ainda Wolkmer (2001, p. 46), “Tal concepção atribui ao Estado Moderno o monopólio exclusivo da produção das normas jurídicas, ou seja, o Estado é o único 
agente legitimado capaz de criar legalidade para enquadrar as formas de relações sociais que vão se impondo".

Nasce o monismo jurídico, "fortemente associada ao declínio do Feudalismo, aos interesses absolutistas da monarquia fortalecida e às novas necessidades de regulamentação centralizadora das práticas mercantis prevalecentes" (WOLKMER, 2001, p. 51). Este é o que Wolkmer (2001, p. 51) denomina de primeiro ciclo do monismo jurídico. 0 segundo ciclo abarca o período da Revolução Francesa até o final das principais codificações do Século XIX. Durante este período,

O Direito Estatal não será mais reflexo da vontade exclusiva de soberanos absolutistas, mas produto da rearticulação das novas condições advindas do Capitalismo concorrencial, da crescente produção industrial, da ascensão social da classe burguesa enriquecida e do liberalismo econômico, condições essas movidas pela lei do mercado, com a mínima intervenção estatal possível.

\section{É neste segundo ciclo onde se verifica}

A gradativa postulação e redução do Direito Estatal ao Direito Positivo, consagra-se a exegese que todo o Direito não só é Direito enquanto produção do Estado, mas, sobretudo, de que somente o Direito Positivo é verdadeiramente Direito. (WOLKMER, 2001, p. 55).

O terceiro ciclo do monismo jurídico é caracterizado por “uma legalidade dogmática com rígidas pretensões de cientificidade e que alcança seu apogeu dos anos 20/30 aos anos 50/60 deste século" (WOLKMER, 2001, p. 57). É neste ciclo monístico que o Direito se impõe enquanto uma "Teoria Pura" kelseniana, "que o Estado é identificado com a ordem jurídica, ou seja, - Estado encarna o próprio Direito em determinado nível de ordenação, constituindo um todo único" (WOLKMER, 2001, p. 57).

Por fim, aduz Wolkmer (2001, p. 58-59), chega-se ao quarto e último ciclo do monismo jurídico situado a partir dos anos 1960/1970. Este período é marcado pelo "esgotamento do paradigma da legalidade que sustentou, por mais de três séculos, a modernidade burguês-capitalista”. Porém, a despeito da crise do modelo legalista caracterizada pela gradual perda de sua funcionalidade e de sua eficácia, “a variante estatal normativista resiste a qualquer tentativa de perder sua hegemonia, persistindo, dogmaticamente, na rígida estrutura lógico-formal de múltiplas formas institucionalizadas" (WOLKMER, 2001, p. 59).

Hodiernamente, portanto, ainda subsiste a ideologia do centralismo jurídico, da identificação do Estado com o Direito, da interdependência mútua entre estes dois entes político e jurídico, sem a qual se tornou inimaginável pensar em um sem o outro.

Consoante ensina Santos (1988, p. 165), “o direito estatal continua a ser, no imaginário social, um direito central, um direito cuja centralidade, apesar de fortemente abalada, é ainda um fator político decisivo" e umas das consequências advindas disso é a falsa crença de que as sociedades tradicionais são sociedades sem Direito.

As sociedades primitivas são sociedades sem Estado, mas não sem Direito. Consoante ensina Barbosa (2001, p. 27), citando Shirley:

Muitas sociedades existiram e ainda existem sem quaisquer leis escritas, ou poder burocrático, ou violência organizada do Estado. Isto não significa que essas sociedades não tenham regras ou normas sociais, nem quer dizer que não há mecanismos de controle social ou sanções contra aqueles que infringem essas regras.

Apenas uma visão etnocêntrica pode sustentar que não se pode imaginar uma sociedade sem Estado e que o Estado é o destino de toda a sociedade, entendendo que "a história tem um sentido único, de que toda sociedade está condenada a inscrever-se nessa história e a percorrer as suas etapas que, a partir da selvageria, conduzem a civilização" (CLASTRES, 1974, p. 3).

Clastres (1974, p. 12) adverte que essa divisão tipológica entre selvageria e civilização só se deu a partir do surgimento do Estado, que forneceu a toda a sociedade o seu elo lógico, traçando uma linha irreversível de descontinuidade entre as sociedades. Essa visão distorcida e imposta pelos Estados modernos ocidentais se pautou na ideia de desenvolvimento ligado à produção material, notadamente a partir do século XIX em decorrência de um pensamento antro- 
pológico denominado de "evolucionismo unilinear". A cultura, para esta corrente de pensamento, "desenvolve-se de maneira mais ou menos uniforme, sendo aceitável pressupor que cada sociedade percorresse as mesmas etapas evolutivas" (BARRETO, 2011, p. 35).

Como aponta Curi (2012, p. 231), as teses antropológicas evolutivas

[...] fundamentam suas teorias na ideia de que toda a humanidade atravessa sucessivamente, seguindo uma única direção, uma trajetória do simples para o complexo, do irracional para o racional, compreendendo três fases de desenvolvimento: a selvageria, a barbárie e, finalmente, a civilização.

Transposto esta ideologia para as sociedades indígenas, nasce a falsa percepção de que é preciso

Civilizar os grupos de cosmovisão primitiva a partir de uma suposição básica de que a cultura moderna é superior à primitiva, baseando-se em ideias do darwinismo social que fundamentam o prevalecimento dos grupos fortes sobre os fracos (BARBOSA, 2001, p. 24).

O índio, nesta concepção, "é um ser "primitivo" e "em processo de evolução" para a condição de "civilizado" ou com os termos empregados pela legislação a caminho da integração à "comunidade nacional"” (BARRETO, 2011, p. 36). Holanda (2008, p. 99) ensina que "foi mediante o gradativo acúmulo de conhecimentos e práticas que o conceito de civilização tornou-se sinônimo de ação sobre os índios". Transposto tal crença para o plano jurídico, a ideologia do desenvolvimento "consiste em considerar desenvolvidas as sociedades que adotaram as técnicas jurídicas ocidentais, onde as codificações são símbolos de desenvolvimento jurídico" (BARBOSA, 2001, p. 33).

Desta forma, ensina Barbosa (2001, p. 36), citando Rouland, houve uma progressiva transferência no plano jurídico dos costumes para as leis, da vingança para a pena, "sendo considerada sanção civilizada pela existência de um aparelho especializado com a intervenção determinante de um terceiro [...] com bastante poder e na condição de representante da sociedade".
Esta visão, entretanto, está bastante equivocada, como demonstra o estudo de campo de Malinowski (2015, p. 53) realizado ao noroeste da Melanésia em 1926. O Direito não se encontra imbrincado à existência de uma sanção oriunda de um poder central, mas é definido a partir de suas funções no campo das relações sociais, que

[...] devem ser buscadas na concatenação das obrigações, no fato de elas serem organizadas em cadeias de serviços mútuos, numa reciprocidade que se estende sobre longos períodos de tempo e cobre amplos aspectos de interesse e atividade.

A lei da sociedade "civilizada" encontra seu análogo na sociedade "primitiva" nos incentivos sociais e psicológicos complexos. Teleologicamente são iguais, uma vez que ocorre a submissão de seus membros no tocante ao comportamento esperado, diferenciando-se, entretanto, no aspecto formal, já que naquela a mensagem é transmitida de forma escrita, nesta a comunicação ocorre por meio das práticas sociais.

As práticas sociais dos povos indígenas caracterizam o seu direito como consuetudinário, sendo este "um conjunto de normas sociais tradicionais, criadas espontaneamente pelo povo, não escritas e não codificadas" (CURI, 2012, p. 231).

Curi, citando Gayosso (2012, p. 236) afirma que

\begin{abstract}
0 direito costumeiro para os povos indígenas atende a uma cosmovisão fundada em princípios ancestrais que está relacionada com a ordem natural dos acontecimentos. São regras aceitas e aplicadas pela sociedade porque a consciência coletiva diz que são boas para os homens. Sua aplicação não requer a inclusão de tais regras em textos normativos, pois o que as tornam legítimas é a consciência comum do grupo que, por meio do conhecimento dos princípios gerais que regem as suas condutas, sustenta as regras determinadas para a resolução de problemas específicos.
\end{abstract}

A força vinculante do costume, consoante Losano (2007, p. 320),

[...] fundamenta-se ou na sanção positiva da reciprocidade (com base na qual o sujeito aceitar adotar um certo comportamento porque a ele vincula uma obrigação de outro na qual está interessado), ou na sanção 
negativa, ou seja, na punição derivada de antepassados reverenciados ou de divindades temidas, ou seja, de seres sobrenaturais.

Villares (2012, p. 23) ensina que "o uso de retribuições e penas para determinadas condutas é constante, mas os pressupostos da pena prevista anteriormente e de algum procedimento formal para impingi-las não é regra”. Portanto, menciona Curi (2012, p. 235),

A afirmação de que os indígenas não têm lei, incutida no senso comum e na compreensão de juristas mais conservadores, é alimentada pela ideia de que a "primitividade" das relações sociais desses povos não comportaria as características do Direito. Uma concepção ultrapassada dentro da antropologia jurídica moderna.

É fato a existência do sistema jurídico indígena, é certo que ele existe, porém, de forma diversificada. Como ensina Souza (2008, p. 9),

Os Direitos indígenas precisam ser compreendidos nos seus próprios termos, isto é, sem serem qualificados ou hierarquizados conforme o padrão do Direito estatal, considerados "não escritos", "sem tribunais" (entres outras qualificadoras negativas) e, desse modo, "inferiores" ou "subsidiários" em relação ao Direito estatal.

São plúrimos os sistemas jurídicos indígenas e não uno, uma vez que os grupos indígenas existentes no território brasileiro são muito diversificados e diferenciados entre si, variando muito em função do contato que tem com a sociedade nacional.

Conforme aduz Barbosa (2001, p. 22):

Há sociedades indígenas em contacto muito antigo com a sociedade brasileira, em condições de dependência quase absoluta, em todos os níveis de sua realidade - econômica, social, política e jurídica - e há sociedades indígenas ainda não contactadas; há, outrossim, extenso leque intermediário.

O certo é que todas as comunidades indígenas possuem o seu próprio regramento, podendo ser análogo ou não ao Direito estatal, a depender do grau de contato que o grupo indígena considerado guarda em relação à sociedade nacional. Apesar desta realidade,
- Estado brasileiro adota a mesma legislação especial para regular toda essa diversidade cultural, "outorgando unilateralmente direitos genéricos através de sua própria lógica jurídica aos indivíduos e às próprias sociedades indígenas" (BARBOSA, 2001, p. 18).

Entretanto, esta postura estatal não é a mais adequada como ensinam Silva e Machado (2014, p. 37), "uma vez que observando os padrões de uma população que não possui os mesmos critérios de criminalidade e moralidade, os mesmo não se sentiriam minimamente responsáveis pelas consequências do ato". Segato (2006, p. 211-212) explica que

\begin{abstract}
A ideia de uma sociedade nacional como uma unidade de base étnica e com as características de uma comunidade moral prescreve continuidades entre a lei e o costume do grupo dominante para todos os habitantes de seu território, afirmando o parentesco entre o sistema legal e o sistema moral desse grupo particular e, portanto, entre o regime de contrato - no qual se baseia a ideia de Constituição e Jurisprudência - e o regime de status, assentado no costume.
\end{abstract}

A despeito deste fato, a legitimidade do Direito das comunidades indígenas mantém-se incólume, uma vez que são "via de regra, restritas ao seu próprio espaço territorial, político e social, elas serão sempre legítimas para os afetados por terem sido criadas e aplicadas por eles próprios" (BARBOSA, 2001, p. 20).

Consoante ensinam Yamada e Belloque (2012, p. 125): "Os sistemas de organização social indígena têm um valor intrínseco à cultura e moral dos povos indígenas, tal como o sistema de organização não indígena representa e se legitima para o não índio”.

Entretanto, apesar dessa suposta igualdade axiológica entre ambas as organizações sociais - indígena e não indígena -, Segato (2006, p. 211) preleciona que não existe o reconhecimento dos costumes indígenas por parte do Estado brasileiro como equivalente à lei positivada, pois

[...] se afirmarmos que a norma moral tradicional vale tanto quanto a lei, estaremos no caminho do reconhecimento pleno da autonomia dos povos originários, mas nos distanciaremos, na maior parte dos casos, do que os instrumentos internacionais promulgam com 
relação aos direitos humanos da mulher e até, em alguns casos, das crianças, entre outras categorias marcadas por um status inferior e dependente.

Apesar disso, o direito de criar e aplicar suas próprias regras de conduta é extraído do princípio da autodeterminação dos povos indígenas, é um direito à coexistência pacífica no interior do Estado com o resto da população, tratando-se de uma descolonização interna.

Amparados pelo princípio da autodeterminação dos povos, não apenas podem como devem os povos indígenas viver no seu território sob o comando de seus regramentos, sob o manto de sua cultura, devendo ser reconhecida pelo Estado sua organização social, costumes, línguas, crenças e tradições, consoante preconiza o art. 231 da Constituição da República Federativa do Brasil. 0 Estado brasileiro, por adotar uma postura monista, não aceita o regramento indígena e entende que deve intervir em suas práticas culturais de modo a normatizar aquilo que para os índios já se encontram normatizados.

Os sistemas jurídicos indígenas, a despeito de existirem de fato, acabam sendo encobertos pela sociedade nacional que impõe o jugo de sua tutela ainda que isto represente uma violação dos direitos fundamentais indígenas, pois, como adverte Villares (2012, p. 24), "se o Direito ignora o pluralismo jurídico e a existência de formas indígenas próprias de resolução de suas ações e conflitos, é colocado em risco o direito individual do índio e o direito coletivo de todo um povo".

\section{REFERÊNCIAS}

ARAÚJO, Ana Valéria; et al. Povos Indígenas e a Lei dos "Brancos": o direito à diferença. Brasília: Ministério da Educação, Secretaria de Educação Continuada, Alfabetização e Diversidade; LACED/ Museu Nacional, 2006.

ASSEMBLÉIA GERAL DAS NAÇÕES UNIDAS, $61^{a}$ sessão. Declaração das Nações Unidas sobre os Direitos dos Povos Indígenas. Nações Unidas, Rio de Janeiro, 2008.
BARBOSA, Marco Antônio. Direito antropológico e terras indígenas no Brasil. São Paulo: Plêiade; Fapesp, 2001.

BARRETO, Helder Girão. Direitos Indígenas: vetores constitucionais. Curitiba: Juruá, 2011.

BRASIL. Estatuto do índio. Lei n⿳0 6001 de 19 de dezembro de 1973. Dispõe sobre o Estatuto do Índio. Brasília, DF, 1973. Disponível em: <http://www. planalto.gov.br/ccivil_03/Leis/L6001.htm>. Acesso em: 4 jan. 2016.

BRASIL. Constituição da República Federativa do Brasil (1988). Disponível em: <http://www.planalto. gov.br/ccivil_03/Constituicao/ConstituicaoCompilado. $\mathrm{htm}>$. Acesso em: 17 maio 2016

BRASIL. Projeto de Lei 2057/91. Dispõe sobre o Estatuto das Sociedades Indígenas. Disponível em: <http://imagem.camara.gov.br/Imagem/d/pdf/ DCD09NOV1991.pdf>. Acesso em: 18 fev. 2016.

\section{CLASTRES, Pierre. A sociedade contra o estado.}

Coletivo Sabotagem, 1974.

CURI, Melissa Volpato. O Direito Consuetudinário dos Povos Indígenas e o Pluralismo Jurídico.

Espaço Ameríndio, Porto Alegre, v.6, n.2, p.230247, jul-dez 2012.

HOLANDA, Marianna Assunção Figueiredo. Quem são os humanos dos direitos? Sobre a criminalização do infanticídio indígena. 2008. Dissertação (Mestrado) - Programa de Pós-Graduação em Antropologia Social, Universidade de Brasília, UNB, Brasília, 2008.

LOSANO, Mario G. Os grandes sistemas jurídicos. SP: Martins Fontes, 2007

MALINOWSKI, Bronislaw. Crime e costume na sociedade selvagem. Petrópolis: RJ, 2015. 
SCOTTI, Guilherme. Direitos Humanos e multiculturalismo: o debate sobre o infanticídio indígena no Brasil. Revista Jurídica da Presidência Brasília, v.15, n.106, jun/set. 2013. Disponível em: <http://www.academia.edu/4629533/Direitos_ Humanos_e_multiculturalismo_o_debate_sobre_o_ infantic\%C3\%ADdio_ind\%C3\%ADgena_no_Brasil>. Acesso em: 13 maio 2016

ESTEVES, Mônica Tatiane Romano. 0 infanticídio dndígena e a violação dos direitos humanos.

2012. 49f. Trabalho (Conclusão de Curso) - Centro Universitário de Brasília (UNICEUB), Brasília, 2012

PAUL AMRY, René. Defensa cultural y pueblosi: propuestas para la actualización del debate. Derecho Penal y Pluralidad Cultural. Anuario de Derecho Penal, 2006.

PIOVESAN, Flávia. Direitos humanos e o direito constitucional internacional. 7.ed. rev. ampl. e atual., SP: Saraiva, 2006.

PONTES, Bruno Cézar Luz. O Índio e a Justiça Criminal Brasileira. In: VILLARES, Luiz Francisco (Coord.). Direito penal e povos indígenas. 2.Reimpr. Curitiba: Juruá, 2012.

ROWEDER, Rainner Jerônimo. A Proteção do Direito dos Povos Indígenas no Brasil: uma relação necessária com os direitos humanos internacionais.

Revista do CAAP, Belo Horizonte, 2010, p.209-225.

SANTOS, Boaventura de Sousa. Uma cartografia simbólica das representações sociais: prolegômenos a uma representação pós-moderna do Direito. Revista Crítica de Ciências Sociais, n.24, Coimbra: CES, 1988

SANTOS FILHO, Roberto Lemos dos. Índios e Competência Criminal - a necessária revisão da súmula 140 do STJ. In: VILLARES, Luiz Francisco (Coord,). Direito penal e povos indígenas. 2.Reimpr. Curitiba: Juruá, 2012.
SEGATO, Rita Laura. Antropologia e direitos humanos: alteridade e ética no movimento de expansão dos direitos universais.

Mana, Rio de Janeiro, v.12, n.1, 2006.

Disponível em: <http://www.scielo.br/scielo. php?pid=S0104931320060001

00008\&script=sci_arttext $>$. Acesso em: 15 maio 2016.

SILVA, Iolanda Catrine; MACHADO, Nélida Reis Caseca. Infanticídio Indígena: o direito à vida sob uma perspectiva cultural. Formiga, Fortaleza, v.5, n.1, p.28-43, jan/junho 2014.

SILVEIRA, Mayra. 0 infanticídio indígena: uma análise à luz da doutrina da proteção integral. 189f. Dissertação (Mestrado em Direito) - PósGraduação em Direito da Universidade Federal de Santa Catarina. 2011. Disponível em: <https://repositorio.ufsc.br/bitstream/ handle/123456789/96005/295138. pdf?sequence=1>. Acesso em: 14 maio 2016 .

SOUZA, Estella Libardi. Povos Indígenas e o Direito à Diferença: do colonialismo jurídico à pluralidade de direitos. In: Congresso Internacional de Pluralismo Jurídico e Direitos Humanos, Universidade Federal de Santa Catarina. Florianópolis, 2008. Disponível em <http:// www.egov.ufsc.br/portal/sites/default/files/ anexos/33234-42224-1-PB.pdf>. Acesso em: 17 maio 2016.

TORRES ROMERO, Sandra. Derecho penal y diversidad cultural. Una mirada a la nueva justicia penal en contexto mapuche. Ilecip. Rev. 004-10, Revista Eletrônica del Instituto Latinoamericano de Estudios en Ciencias Penales y Criminología, 2009.

VILLARES, Luiz Fernando. Direito penal e povos indígenas. In: VILLARES, Luiz Francisco (Coord.).

Direito penal e povos indígenas. 2. Reimpr. Curitiba: Juruá, 2012. 
WOLKMER, Antonio Carlos. Pluralismo jurídico. Fundamentos de uma nova cultura jurídica no direito. 3.ed. São Paulo: Alfa Ômega, 2001.
YAMADA, Erika M; BELLOQUE, Juliana G. Pluralismo jurídico: direito penal, direito indígena e direitos humanos - uma análise do art. 121 do código penal brasileiro. In: VILLARES, Luiz Francisco (Coord.).

Direito penal e povos indígenas. 2.Reimpr. Curitiba: Juruá, 2012. 
